DOI: https://doi.org/10.24867/12AM04Petkovic

\title{
ANALITIČKI I NUMERIČKI POSTUPCI ANALIZE NAPONA I DEFORMACIJA U CILINDRIČNIM SUDOVIMA POD PRITISKOM
}

\section{ANALYTICAL AND NUMERICAL PROCEDURES FOR STRESS AND STRAIN ANALYSIS IN CYLINDRICAL PRESSURE VESSELS}

\author{
Strahinja Petković, Fakultet tehničkih nauka, Novi Sad
}

\section{Oblast - MAŠINSKO INŽENJERSTVO}

Kratak sadržaj - $U$ ovom radu analizirana su naponska $i$ deformacijska stanja cilindričnih sudova pod pritiskom. Različiti slučajevi dobijeni su odabirom različitih modela cilindričnih sudova koji se najčešce sreću u praktičnim primenama. Izvršena je detaljna analiza i poređenje teorijskih i numeričkih rezultata za slučajeve kada je cilindrični sud opterećen unutrašnjim pritiskom. Takođe, izvršena je analiza uticaja toplotnog opterećenja na raspodelu karakterističnih napona $i$ deformacija. Analitička rešenja dobijena su na osnovu klasične teorije za beskonačno dugačke elastične cevi konačne debljine i slučaj ravanskog stanja deformacije. Posebna pažnja posvećena je analizi napona $i$ deformacija u okolini spojeva (poklopaca) $i$ njihovom poređenju sa rezultatima za otvoreni cilindrični sud. Za modele realnih sudova, približna numerička rešenja dobijena su korišćenjem aplikacije Solidworksi adekvatne numeričke metode konačnih elemenata (MKE). Poređenje rezultata i prikaz rešenja dat je grafički $u$ vidu dijagrama i odgovarajuci $3 D$ modela.

Ključne reči:sudovi pod pritiskom, teorija elastičnosti, MKE metode.

\begin{abstract}
In this paper, the stress and strain of cylindrical pressure vessels are analyzed. Different cases were obtained by selecting different models of cylindrical vessels that are most commonly encountered in practical applications. A detailed analysis and comparison of theoretical and numerical results for the cases when the cylindrical vessel is loaded with internal pressure was performed. Also, the influence of the thermal load on the distribution of characteristic stresses an deformationis given. Analytical solutions were obtained on the basis of the classical theory for infinitely long elastic tubes of finite wall thickness and in the case of the plane state of deformation. Special attention is dedicated to the analysis of stresses and strains in the vicinity of joints (caps). For real world models, approximate numerical solutions were obtained using Solidworks application and adequate FEM procedure. The comparison of results and presentation of solutions is given graphically in the form of diagrams and corresponding 3D models.
\end{abstract}

Keywords: pressure vessels, theory of elasticity, FEM.

\section{NAPOMENA:}

Ovaj rad proistekao je iz master rada čiji mentor je bio dr Damir Mađarević, van. prof.

\section{UVOD}

Uređaji i konstrukcije (rezervoari, cevovodi, silosi, kotlovi, reaktori) koji prenose, skladište ili primaju fluide (tečnosti i gasove) se nazivaju sudovi pod pritiskom [1,2]. Unutrašnji pritisak kod ovakvih konstrukcija je obično veći od spoljašnjeg pritiska. Sudovi pod pritiskom često su izloženi visokom pritisku kao i visokoj temperaturi, a u nekim slučajevim zapaljivim fluidima kao i radioaktivnim materijalima. Takođe, fluid u sudu može menjati agregatno stanje kao što je to slučaj kod parnih bojlera i kotlova. Zbog velike opasnosti veoma je važno da se sudovi pod pritiskom konstruišu tako da se predvidi svaka mogućnost nastanka havarije u vidu curenja ili ekstremnih situacija (eksplozija), odnosno da se projektuju tako da mogu podneti visoke radne temperature i pritiske. Veličina i oblik sudova pod pritiskom varira od velikih cilindričnih sudova koji služe sa skladištenje gasova pod velikim pritiskom do malih hidrauličnih cilindara na avionima za upravljanje elementima krila i točkova. Neki se nalaze smešteni duboko ispod površine zemlje ili okeana, dok se većina koristi na površini zemlje. Sudovi pod pritiskom su obično sfernog ili cilindričnog oblika.

Cilindrični sudovi se najčešće prave tako što se limovi odgovarajuće debljine savijaju i spajaju u konačni oblik. Spajanje se vrši zavarivanjem pod strogo kontrolisanim uslovima. Cilindrični sudovi pod pritiskom manjih dimenzija izrađuju se tako što se na cev određene dužine na oba kraja zavare završeci (krajevi, poklopci) koji mogu biti različitog oblika (ravni ili zaobljeni poklopci). U praksi se sudovi pod pritiskom najčešće izrađuju u obliku cilindričnog suda zbog lakše proizvodnje i boljeg iskorišćenja radnog prostora, iako je poznato da sferni sudovi imaju povoljnije naponsko stanje tj. bolje podnose radno opterećenje (kotlovi, izmenjivači toplote, hemijski reaktori).

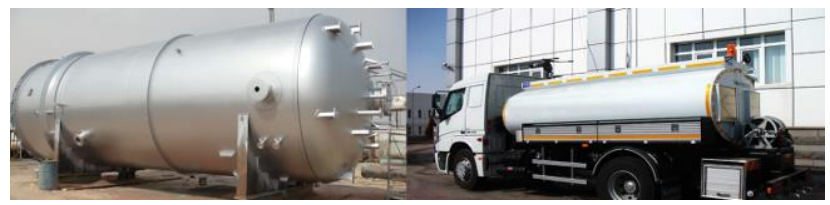

Slika 1. Primeri cilindričnih sudova

$\mathrm{U}$ radu je sprovedena detaljna analiza analitičkih rezultata dobijenih korišćenjem klasične teorije za beskonačno dugačke elastične cevi konačne debljine i slučaj ravanskog stanja deformacije [3]. Rezultati teorijske analize su upoređeni sa pažljivo pripremljenim numeričkim rezultatima. Numerička analiza sprovedena je korišćenjem metode konačnih razlika i metode konačnih elemenata [4]. 
Sve analize i poređenje rezultata izvršene su za dva karakteristična slučaja radnog opterećenja:

1. Unutrašnji radni pritisak (1Mpa -10 bara)

2. Toplotno opterećenje (razlika temperatura unutrašnjeg i spoljašnjeg zida suda $\Delta \mathrm{T}=3^{\circ} \mathrm{C}$, temperatura radnog fluida iznosi $90^{\circ} \mathrm{C}$ ).

Analizirano je nekoliko karakterističnih konstriktivnih slučajeva (Slika 2):

1. Otvoreni cilindrični sud (teorijski slučaj beskonačno dugačka cev),

2. Cilindrični sud sa ravnim poklopcima,

3. Cilindrični sud sa hemisferičnim poklopcima,

4. Sferni sud,

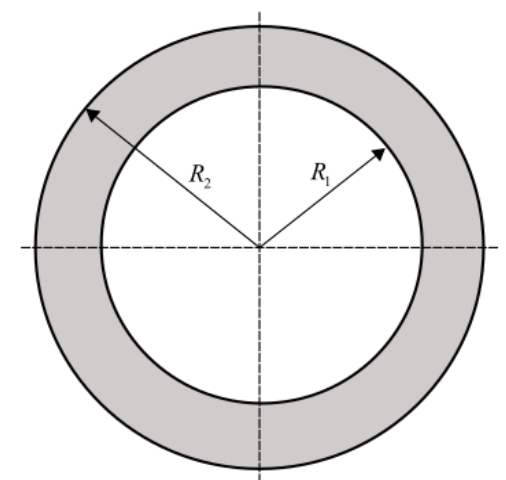

Slika 2: Konstruktivne mere analiziranih sudova pod pritiskom: unutrašnji poluprečnik:

$R_{1}=250 \mathrm{~mm}$, spoljašnji poluprečnik: $R_{2}=300 \mathrm{~mm}$.

Dužina svih analiziranih sudova iznosi $L=1,5 \mathrm{~m}$ (Slika 3 ).

U svakom od prethodno nabrojanih slučajeva izvršene su sledeće analize:

- analiza radijalnih i cirkularnih napona u zidu suda,

- analiza deformacija suda (radijalnog pomeranja)

- termo-mehanička analiza (analiza napona i deformacija pod dejstvom unutrašnjeg pritiska i toplotnog opterećenja).

Termo-mehaničke analize koriste se za proučavanje toplotnih opterećenja, toplotnog fluksa, napona i deformacija. Proučavanje toplotnih opterećenja sudova pod pritiskom je od velikog značaja imajući u vidu da pored toga što sudovi služe za skladištenje i transport fluida čija se temperatura značajno razlikuje od spoljašnje temperature ambijenta, velike temperaturne promene mogu nastati prilikom punjenja i pražnjenja suda.

Postoje dve vrste ovih analiza: statičke i dinamičke (stacionarne i tranzijentne). U cilju lakšeg poređenja uticaja različitih vrsta opterećenja i rezultata, u radu je sprovedena stacionarna termo-mehanička. Ona je u skladu sa stacionarnim mehaničkim opterećenjem $u$ vidu konstantnog unutrašnjeg hidrostatičkog pritiska.

Poređenje sa teorijskim rezultatima za otvoreni cilindrični sud izvršeno je na sredini suda i u neposrednoj blizini spoja sa odgovarajućim poklopcima.

U poglavlju 2 ovog rada dat je kratak prikaz teorijskih postavki ravanske analize deformacija sa naponskom analizom. U praksi se prilikom projektovanja sudova pod pritiskom analiziraju naponi i deformacije korišćenjem osnovne teorije za tankozidne cevi opterećene unutrašnjim pritiskom. Iz tog razloga u uvodnom delu opisana je naponska i deformacijska analiza tankozidnih sudova pod pritiskom. U nastavku je dat prikaz teorije koja se koristi pri analizi. sudova pod pritiskom konačne debljine zida.

U poglavlju 3 dat je prikaz numeričkih rešenja i prikaz poređenja sa teorijskim rezultatima.

U poslednjem delu ovog rada dat je kratak zaključak rada sa smernicama za dalji rad.

\section{TEORIJSKE OSNOVE SUDOVA POD PRITISKOM}

Do loma konstrukcija dolazi na mestima lokalne koncentracije napona tj. kada vrednosti ekvivalentnog napona prekorače dozvoljene vrednosti napona materijala suda. Kod sudova pod pritiskom se to najčešće dešava na mestima geometrijskih singulariteta: spojevi sa drugim elementima i zavareni spojevi. Kako su sigurnost i bezbednost funkcionisanja kod ovakvih konstrukcija od presudne važnosti, pred inženjere se postavljaizazov modeliranja i određivanja napona i deformacija koji se mogu očekivati u praktičnim uslovima.

Većina standardnih proračuna sudova pod pritiskom zasniva se na korišćenju jednostavnih izraza za određivanje napona i deformacija za slučaj statičkog opterećenja i činjenice da je debljina suda mala u odnosu na dimenzije suda.

Međutim, uzimanjem u obzir debljine suda, analiza je složenija ali nam omogućava precizniji uvid u promenu karakterističnih napona u unutar zida suda.

U slučaju da cilindrični sud opteretimo konstantnim unutrašnjim pritiskom $p$ imaćemo prostorno naponsko stanje u zidu suda gde su sa označeni naponi $\sigma_{r}$ radijalni napon, $\sigma_{z}$ aksijalni napon, a $\sigma_{\theta}$ cirkularni napon.

\subsection{Tankozidni cilindrični sudovi pod pritiskom}

Teorijska analiza napona kod tankozidnih cilindričnih sudova pod pritiskom podrazumeva zanemarivanje uticaja težine suda kao i težina fluida u sudu.
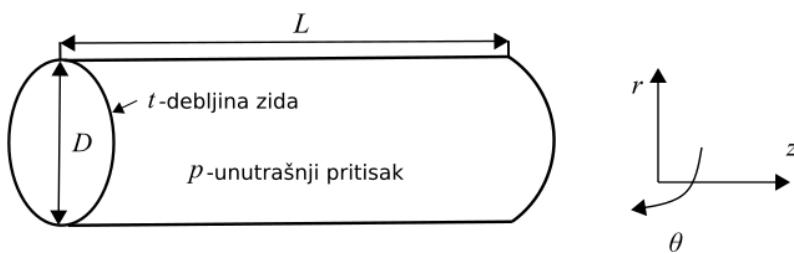

Slika 3: Cilindrični sud pod pritiskom

Na Slici 3 sa $r$ je označen radijalni pravac, $\theta$ je cirkularni pravac, $z$ aksijalni pravac, a $L$ predstavlja dužinu suda.toznačava debljinu suda, $D$ unutrašnji prečnik suda, $p$ predstavlja unutrašnji pritisak.
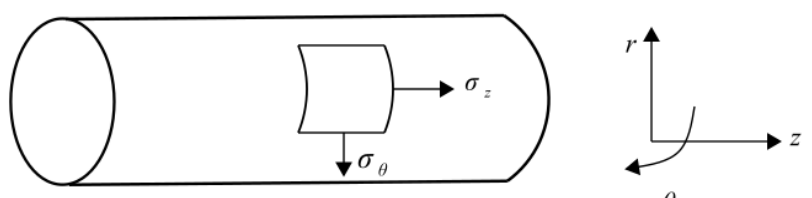

Slika 4: Naponi u tankozidnom cilindričnom sudu 


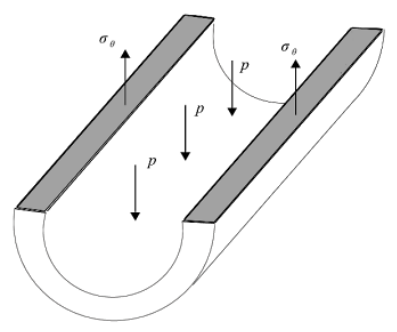

Slika 5: Tankozidni sud - određivanje cirkularnog napona

Iz uslova ravnoteže spoljašnjeg opterećenja i unutrašnjih sila određujemo cirkularni napon:

$$
\begin{aligned}
D L p & =2 \sigma_{\theta} L t, \\
\sigma_{\theta} & =\frac{p D}{2 t} .
\end{aligned}
$$

$\mathrm{Na}$ sličan način analizom ravnoteže duž ose suda, dobijamo izraz za aksijalni napon:

$$
\sigma_{z}=\frac{p D}{4 t} .
$$

Kod tankozidnih sudova pod pritiskom prečnik suda je mnogo veći od debljine cilindra $D>t$, pa se može zaključiti da je $\sigma_{\theta}, \sigma_{z} \gg \sigma_{r}$, tako da vrednost $\sigma_{r}$ je zanemarljiva, odnosno da je u ovom slučaju naponsko stanje ravansko (Slika 4).

$\mathrm{U}$ nastavku rada, aksijalni napon $\sigma_{z}$ nije bio predmet analize.

\subsection{Sudovi pod pritiskom konačne debljine zida}

Posmatrajmo elementarni segment cilindičnog suda konačne debljine zida na Slici 7. Na osnovu analize napona možemo zapisati jednačinu ravnoteže u radijalnom pravcu:

$$
\begin{aligned}
& \left(\sigma_{r}+d \sigma_{r}\right)(r+d r) d \theta \times 1-\sigma_{r} \times r d \theta \times 1= \\
& =2 \sigma_{\theta} \times d r \times 1 \times \sin \frac{d \theta}{2}
\end{aligned}
$$

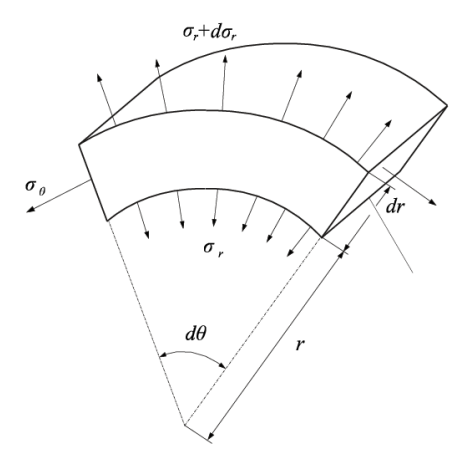

Slika 6: Analiza radijalnog napona

Zanemarivanjem članova drugog reda jednačina (4) se može napisati na sledeći način:

$$
\sigma_{\theta}-\sigma_{r}=r \frac{d \sigma_{r}}{d r} .
$$

Imajući u vidu pretpostavku o ravanskom stanju deformacije $\varepsilon_{z}=0$, prethodna diferencijalna jednačina se može napisatu u sledećem obliku:

$$
\frac{d}{d r}\left(\sigma_{r} r^{2}-A r^{2}\right)=0 .
$$

Nakon integracije dobijamo:

$$
\sigma_{r} r^{2}-A r^{2}=\text { const. }=-B .
$$

odnosno raspored radijalnog i cirkularnog napona u zidu suda:

$$
\begin{gathered}
\sigma_{\theta}=A+\frac{B}{r^{2}}, \\
\sigma_{r}=A-\frac{B}{r^{2}},
\end{gathered}
$$

gde konstante $A$ i $B$ određujemo iz uslova opterećenja suda.

\section{ANALIZA NAPONA I DEFORMACIJA ZA CILINDRIČNI SUD KONAČNE DEBLJINE SA HEMISFERIČNIM POKLOPCIMA}

Za prikaz rezultata rada izabran je slučaj cilindričnog suda sa hemisferičnim poklopcima gde smo izvršili detaljnu FEM analizu i prikazali napone u poprečnim presecima na sredini suda $\mathrm{i}$ neposredno u blizini hemisferičnih poklopaca.

Numerička analiza je sprovedena na sledeći način:

- kreiranje geometrije sudova pod pritiskom,

- definisanje svojstava materijala elemenata konstrukcije,

- diskretizacija geometrije - generisanje adekvatne prostorne mreže imajući u vidu osno-simetričnost elemenata konstrukcije suda,

- postavljanje različitih graničnih uslova i uslova opterećenja,

- rešavanje modela i prikaz rezultata.

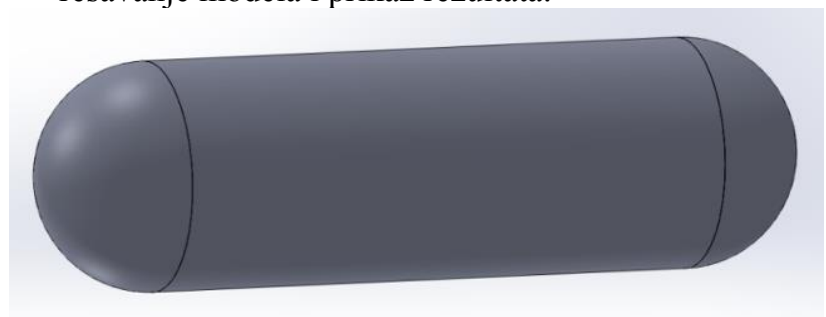

Slika 7: Geometrija cilindričnog suda sa hemisferičnim krajevima

Na Slici 8 prikazan je prostorni raspored radijalnih napona pod dejstvom unutrašnjeg pritiska $p$ gde je jasno uočljiva pojava koncentracije napona u delu hemisferičnog poklopca dok cirkularni naponi u ovom slučaju imaju ravnomerniju raspodelu (Slika 9). Ekstremne vrednosti napona date su su u Tabeli 1.

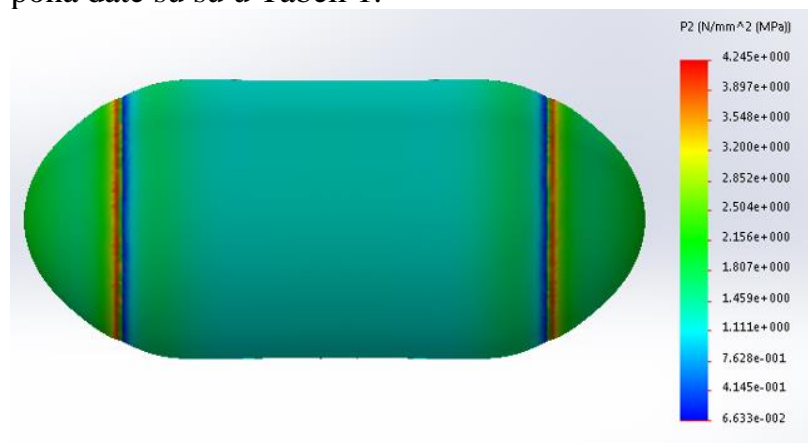

Slika 8: Radijalni napon za unutrašnji radni pritisak $\mathrm{p}_{1}=1 \mathrm{MPa}$ 


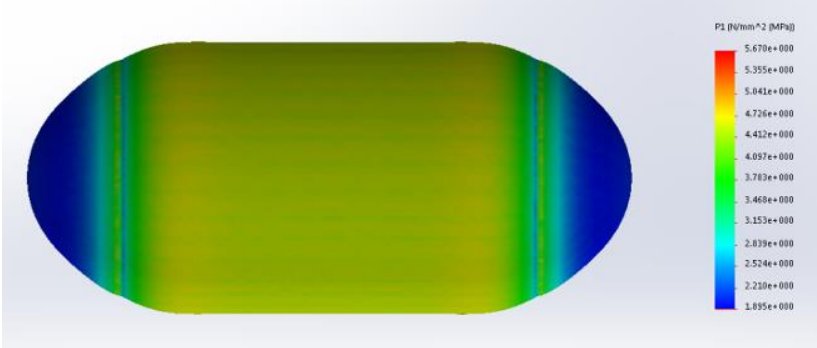

Slika 9: Cirkularni napon za unutrašnji radni pritisak $\mathrm{p}_{1}=1 \mathrm{MPa}$

Tabela 1: Ekstremne vrednosti napona u cilindričnom sudu sa hemisferičnim krajevima $p=1 \mathrm{MPa}$

\begin{tabular}{|c|c|c|}
\hline $\mathrm{p}_{1}=1 \mathrm{MPa}$ & $\sigma_{r}$ & $\sigma_{c}$ \\
\hline $\min$. & 0,066 & 1,895 \\
\hline $\max$. & 4,245 & 5,670 \\
\hline
\end{tabular}

U Tabeli 2 prikazano je poređenje maksimalnih i minimalnih vrednosti napona $\mathrm{u}$ karakterističnim presecima sa teorijskim vrednostima za beskonačno dugačku cev.

Tabela 2: Vrednosti napona u cilindričnom sudu sa hemisferičnim krajevima za različite slučajeve opteré́enja

\begin{tabular}{|l|c|c|c|c|}
\hline & \multicolumn{2}{|c|}{$\begin{array}{c}\text { Teorijska } \\
\text { analiza (MPa) }\end{array}$} & \multicolumn{2}{c|}{$\begin{array}{c}\text { Numerička } \\
\text { analiza (MPa) }\end{array}$} \\
\hline $\mathrm{p}=1 \mathrm{MPa}$ & $\sigma_{r}$ & $\sigma_{c}$ & $\sigma_{r}$ & $\sigma_{c}$ \\
\hline $\begin{array}{l}\text { Sredina suda } \\
\text { (min.) }\end{array}$ & -1 & 4,545 & $-0,96$ & 4,534 \\
\hline $\begin{array}{l}\text { Sredina suda } \\
\text { (max.) }\end{array}$ & 0 & 5,545 & $-0,0164$ & 5,567 \\
\hline $\begin{array}{l}\text { Spoj poklopca } \\
\text { (min.) }\end{array}$ & -1 & 4,545 & $-0,975$ & 3,637 \\
\hline $\begin{array}{l}\text { Spoj poklopca } \\
\text { (max.) }\end{array}$ & 0 & 5,545 & $-0,034$ & 4,253 \\
\hline $\begin{array}{l}\mathrm{p}=1 \mathrm{MPa} \\
+\Delta \mathrm{T}=3^{\circ} \mathrm{C}\end{array}$ & $\sigma_{r}$ & $\sigma_{c}$ & $\sigma_{r}$ & $\sigma_{c}$ \\
\hline $\begin{array}{l}\text { Sredina } \\
\text { suda(min.) }\end{array}$ & -1 & $-0,659$ & $-2,208$ & 1,048 \\
\hline $\begin{array}{l}\text { Sredina suda } \\
\text { (max.) }\end{array}$ & 0 & 10,041 & 0,209 & 8,478 \\
\hline $\begin{array}{l}\text { Spoj poklopca } \\
\text { (min.) }\end{array}$ & -1 & $-0,659$ & $-2,943$ & $-0,636$ \\
\hline $\begin{array}{l}\text { Spoj poklopca } \\
\text { (max.) }\end{array}$ & 0 & 10,041 & 0,307 & 7,622 \\
\hline
\end{tabular}

\section{ZAKLJUČAK I PRAVCI DALJIH ISTRAŽIVANJA}

U radu su analizirana naponska i deformacijska stanja cilindričnih sudova pod pritiskom. Izvršena je detaljna analiza i poređenje teorijskih i numeričkih rezultata za slučajeve kada je cilindrični sud opterećen unutrašnjim pritiskom i toplotnim opterećenjem od zagrejanog radnog fluida. Numerička analiza sprovedena je korišćenjeg programskih paketa Mathematica i Solidworks.

$\mathrm{Na}$ osnovu poređenja rezultata u dva karakteristična poprečna preseka suda (sredina i neposredna blizina spoja sa poklopcima) utvđeno je da se teorijske vrednosti napona ne odstupaju značajno od numeričkih tj. da se teorijski proračuni mogu koristiti za kvalitativnu ocenu stvarnog opterećenja suda. Kada je u pitanju uticaj toplotnog opterećenja, čak i pri minimalnim temperaturnim razlikama spoljašnjeg i unutrašnjeg zida suda, vrednosti napona u ovom slučaju se značajno razlikuju od teorijskih vrednosti, što prilikom projektovanja treba uzeti u obzir.

\section{LITERATURA}

[1] A.P. Boresi, R.J. Schmidt, "Advanced mechanics of materials”, New York, Wiley, 1993.

[2] S. Chattopadhyay, "Pressure Vessels", Boca Raton, CRC Press, 2004.

[3] M. H. Sadd - "Elasticity: Theory, Applications, and Numerics” 1st Edition 2005.

[4] A. Kaw, S. Ho, "On Introducing Approximate Solution Methods in Theory of Elasticity” Wiley Periodicals, Inc. Comput Appl Eng Educ Vol 14: pp. 120-134, 2006; DOI 10.1002/cae.20070

\section{Kratka biografija:}

Strahinja Petković rođen je u Novom Sadu 1991. godine. Diplomski (bečelor) rad na Fakultetu tehničkih nauka iz oblasti Mašinstva - Tehnička mehanika i dizajn u tehnici odbranio je 2017.godine.

kontakt: strale0000@yahoo.com

Damir Mađarević rođen je u Novom Sadu 1981. Doktorirao je na Fakultetu tehničkih nauka 2013. godine., a od 2020. godine je zvanju vanredni profesor. Oblast interesovanja: termo-mehanika, prostiranje talasa u gasovima 